Criação / Artes Visuais 



\section{Guignard, o mestre}

\section{MARIA HELENA ANDRÉS}

Q

UANDO Alberto Da Veiga guignard chegou a Minas Gerais, em fins de 1943, a convite do então prefeito Juscelino Kubitschek, trouxe consigo uma bagagem artística já consolidada pela crítica. Desde essa época, era respeitado como grande artista e reconhecido internacionalmente. Na década de 40 passou três anos em Itatiaia, estado do Rio, e foi ali que recebeu a notícia de que sua Noite de São João acabara de ser adquirida pelo Museu de Arte Moderna de New York.

Guignard sempre se deu bem nas montanhas. Em carta a Portinari, dizia: "Sabes que sou montanhês e por isso, forte de saúde". Deslocando-se para Belo Horizonte, descobriu a luminosidade dos céus de Minas. As montanhas the ofereciam cenário para paisagens líricas, transparentes, igrejas surgindo da bruma, balões coloridos subindo aos céus.

Naquela época, a arte em Minas Gerais ainda estava ligada a um academismo formal. A presença de Guignard em Belo Horizonte trouxe uma completa renovação para o meio artístico. Juscelino Kubitschek abria novas direções para a arquitetura, criando o conjunto da Pampulha, convidando o maestro Bosmans para dirigir a orquestra sinfônica e Guignard para tomar sob sua direção a Escola de Belas Artes.

Um grupo de jovens se reuniu em torno desse artista vindo do Rio de Janeiro, amigo de Portinari, Di Cavalcanti e Santa Rosa.O Parque Municipal servia de inspiração para o mestre e seus discípulos. Exuberante, cheio de entusiasmo, conduzia seus alunos a longas caminhadas pelas alamedas do parque. Antes de começar o desenho, eles teriam de aprender a ver, a sentir a natureza em seu silêncio. A atenção consciente no agora, a observação da realidade exterior com a interioridade de cada um, possibilitava o despertar da liberdade criadora.

A carreira de Guignard como mestre teve início na Fundação Osório, no Rio de Janeiro. Desde essa época, ele estimulava o crescimento interno do aluno.

Guignard não perdeu a inocência das crianças. Durante toda sua vida manteve a espontaneidade criadora e pintou naturalmente, como cantam os pássaros. A espontaneidade, a alegria, o entusiasmo pela vida, o prazer de descobrir cores novas nos céus e nas montanhas, nos reflexos das águas, nos cortes das árvores, nas manchas dos muros velhos, eram qualidades inerentes à sua personalidade.

Guignard estendia esse entusiasmo aos seus alunos. A natureza era seu ponto de referência. "Olhe, o colorido dos céus de Minas Gerais tem um brilho diferente, repare as árvores, as folhagens, as raízes...”. 
Sua disciplina não se fundamentava em conceitos teóricos, mas na experiência: era observação, concentração e integração total da pessoa com a paisagem. O aluno, desprovido de recursos fáceis, submetido ao lápis duro, sem borracha, acabava afinando-se com a beleza de um olho humano e tinha uma semana para terminar o desenho de um rosto. O prazer não estava em terminar rápido, mas na própria concentração exigida pelo trabalho, no próprio ato de fazer, paciente e silencioso, no uso das mãos, no artesanato metódico e limpo. O desenvolvimento da percepção era também um dos caminhos para o autoconhecimento e a auto-expressão. Criatividade e disciplina, liberdade e concentração, espontaneidade e reflexão fundiam-se dentro do mesmo estímulo.

A personalidade de Guignard como mestre delineia-se com maior nitidez mediante o confronto de seu método revolucionário de ensino, baseado no apoio à iniciativa pessoal, com o ensino nas escolas de arte de orientação acadêmica. As escolas acadêmicas prevaleciam nos grandes centros brasileiros quando Guignard chegou a Minas. Aos conhecimentos adquiridos na Europa, ele aliava seu grande poder intuitivo para desvendar o caminho ainda obscuro do ensino moderno, no qual técnica e capacidade criadora se desenvolvem de maneira conjugada, o lápis não reproduz a fria documentação de um objeto, mas transmite toda a força emocional de um momento de criação.

Nessa orientação artística, o aluno não visa apenas o recebimento de um simples diploma ao final de um currículo, mas a vivência de uma formação estética que não termina no período de aprendizagem, mas prolonga-se por toda a vida. De acordo com essa visão, a arte constitui uma riqueza insubstituível, porque se apóia numa estrutura viva e espiritual e não apenas no interesse imediato. Procura a integração do homem ao universo, através do desenvolvimento de suas aptidões individuais.

Mais do que ninguém, Guignard conseguia vislumbrar a coisa nova, a individualidade que se revela na variedade de temperamentos humanos, agora estudados com grande interesse à luz da psicologia moderna. Observações feitas à margem de um catálogo, referindo-se às tendências de cada aluno em particular, revelam esse senso profundo para descobrir vocações e conhecer temperamentos. Uma concepção ampla da realidade humana o levava a valorizar tanto o aluno que desenhava realisticamente um retrato a lápis duro, quanto aquele que se afastava por completo do modelo, para imprimir na tela imagens subjetivas. Ao se dirigir ao aluno, seus olhos enxergavam através da insegurança, conseguiam vislumbrar o traço feliz, a mancha de cor e todas as possibilidades que se escondem atrás de um tímido desenho.

Guignard era simples e possuia a humildade daqueles que são realmente grandes. Não via no aluno um futuro concorrente, mas um companheiro de arte que despertava diante de seus olhos. Muitas vezes, ao criticar um trabalho, seu entusiasmo chegava a ser comovente: "Você desenha melhor do que eu", escutei-o dizer a um colega, "mas deixa estar que ainda chegarei lá". Ao corrigir o trabalho de um aluno ele muitas vezes se entusiasmava e o assinava. 
Em 1447, Guignard me presenteou com um quadro, representando um caminho no Parque Municipal de Belo Horizonte. Esse quadro sugeriu o título para o meu livro Os caminhos da arte. Mais tarde, depois de sua morte, descobri debaixo de um de meus desenhos uma pequena aquarela de Guignard representando os céus de Minas. Foi exatamente na época em que iniciei a minha fase de naves espaciais.

Trabalhando junto com seus alunos, Guignard reviveu de maneira quase única o antigo mestre, figura desaparecida nos tempos modernos. Atualmente, o ensino se distribui em diversas cátedras, com horários marcados e contato reduzido do professor com os alunos. Anteriormente às academias de Belas Artes, o mestre - fosse ele filósofo ou artesão - trabalhava lado a lado com seus aprendizes e a eles se misturava, sem preocupação de superioridade, desejando apenas transmitir experiências. Assim foi Guignard, o mestre moderno, que ensinava uma arte de vanguarda, não ditava leis, mas fazia o aluno descobrir o equilíbrio e a proporção no próprio trabalho, sem demonstrações dogmáticas.

Mestre autêntico, não julgava segundo suas inclinações e preferências, mas desinteressadamente, compreendia o aluno e o conduzia. Ele não trazia valores fixos a decretar - despertava valores novos no contato de sua presença, de seu estímulo.

A influência de Guignard sobre seus alunos não pode ser medida pela melhor maneira de copiar o mestre em suas telas, mas na maneira de segui-lo em seu entusiasmo pela arte, seu amor pela natureza e pelas crianças, seu lirismo perante a vida, seu desprendimento pelo dinheiro, seu estímulo à pesquisa e à iniciativa individual. Juntamente com o aprendizado técnico, Guignard procurava formar no aluno toda uma filosofia de vida.

Sua disciplina não se fundamentava em conceitos teóricos, mas na experiência. Guignard era curioso, gostava de observar cenas de rua e registrá-las em pequenos croquis. Escondia-se atrás das árvores para não ser visto. Um dia, encontrei-o numa avenida central de Belo Horizonte, captando as cenas dolorosas de um enterro. Tentava passar despercebido, mas as crianças, sentadas no meiofio repetiam em coro:

- Ei, Guignard!

Guignard tentava impedir a imprudência das crianças, mas elas continuavam a importunar o mestre, gritando mais alto ainda:

- Olha o Guignard desenhando!

Os pequenos croquis que fazia nas ruas, serviam de motivação para futuros quadros. Recomendava registrar os acontecimentos do cotidiano, captar o momento presente em sua intensidade emocional, para depois recriá-los no papel ou na tela:

- "Façam croquis do natural, estejam atentos ao movimento das ruas, aos 
mercados, às feiras, às festas de $\mathrm{S}$. João, aos casamentos, aos enterros... O croquis é necessário, ele é a base de tudo!"

Guignard detestava o academismo gerador de formas estereotipadas. O importante era o nascimento do novo. O que realmente pertencia à essência do aluno. Disciplina e liberdade se conjugavam para a formação dos alunos, não somente no nível estético, mas também no plano do desenvolvimento humano.

Maria Helena Andrés é artista plástica, escritora e ex-aluna de Guignard. Reside em Belo Horizonte.

Parte deste texto foi extraída do livro da autora Os caminhos da arte, publicado pela Editora Vozes, Petrópolis, 1977.

Foram alunos de Guignard, em Minas Gerais, entre outros, os seguintes artistas plásticos: Aparecida Carvalho Barbosa, Bax, Chanina Sznbejn, Heitor Coutinho, Amilcar de Castro, Holmes Neves, Laetitia Renault, Álvaro Apocalypse, Jarbas Juarez, Wilde Lacerda, Aneto, Vilma Rabelo, Ione Fonseca, Santa, Sara Ávila, Leda Gontijo, Haroldo Matos, Wilma Martins, Maria Helena Andrés, Lizete Meinberg, Eduardo de Paula, Ruth Michel Perrela, Yara Tupinambá, Solange Botelho, Jeferson Lodi, Amarylles Coelho Teixeira, Marília Giannetti Torres, Mário Silésio, Estevão José de Souza, Mary Vieira, Gavino Mudado Filho, Nina Xavier, Melo Alvarenga, Augusto Degois, Washington Filho e Célia Laborne Tavares. 

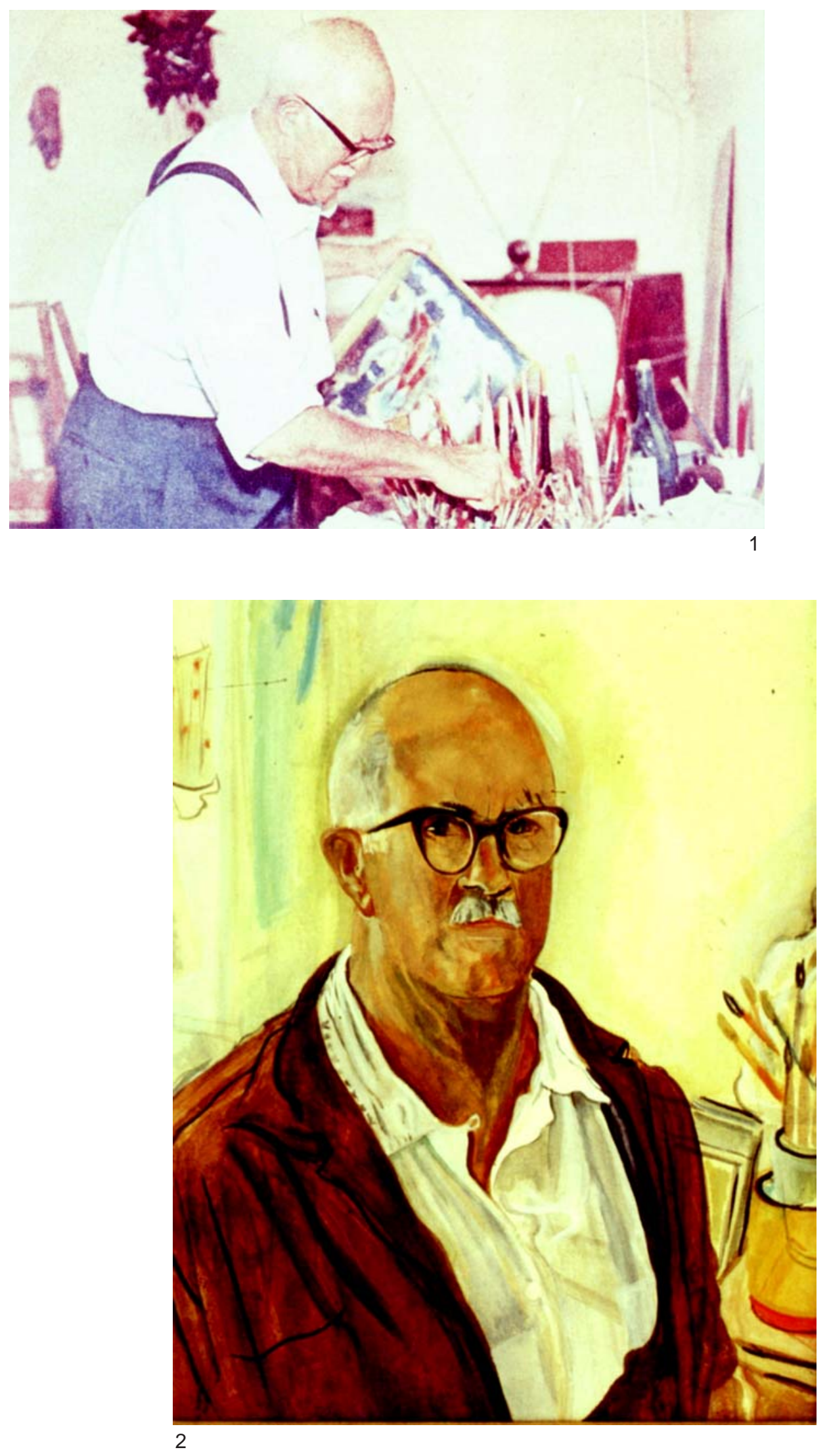


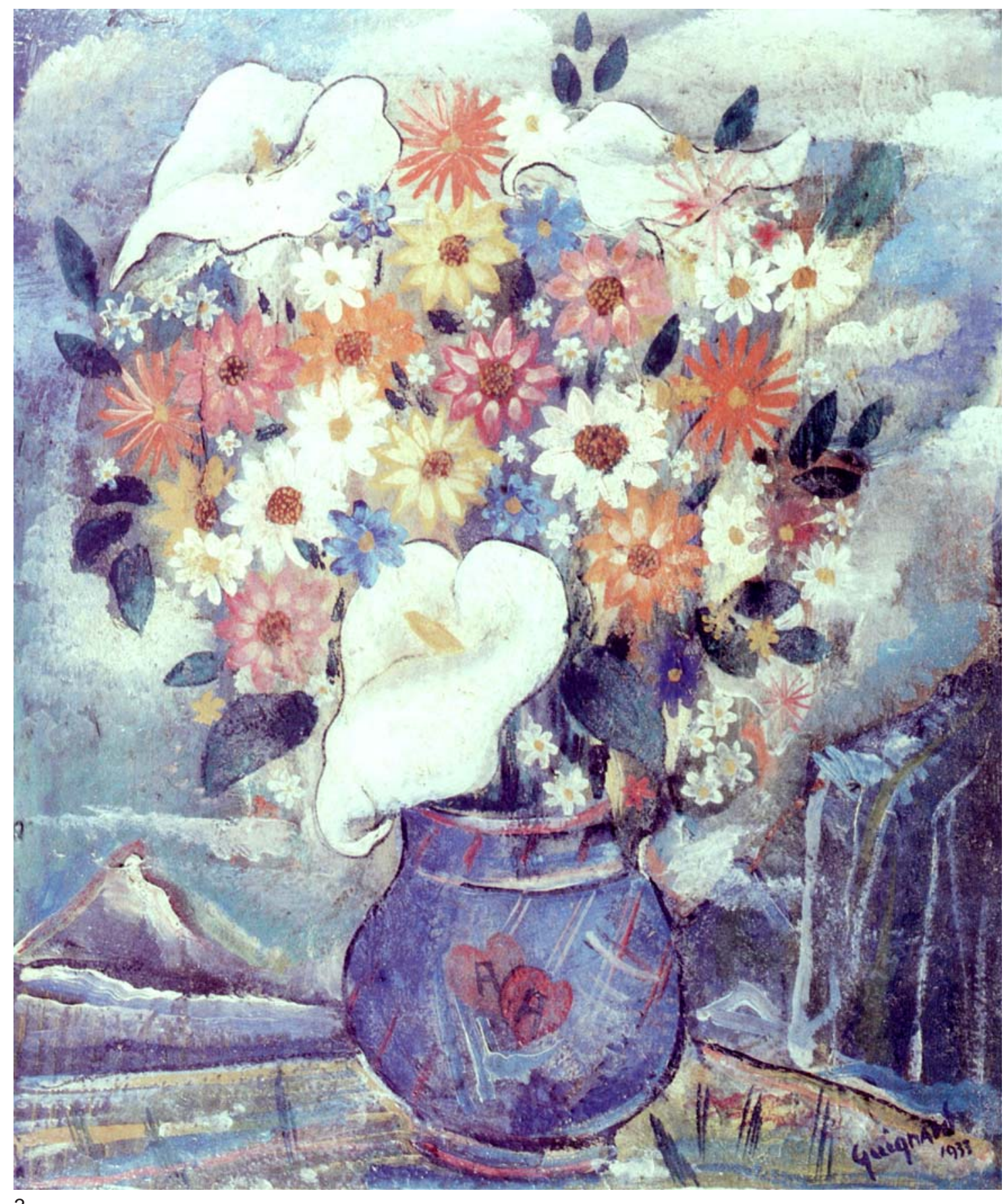

3 


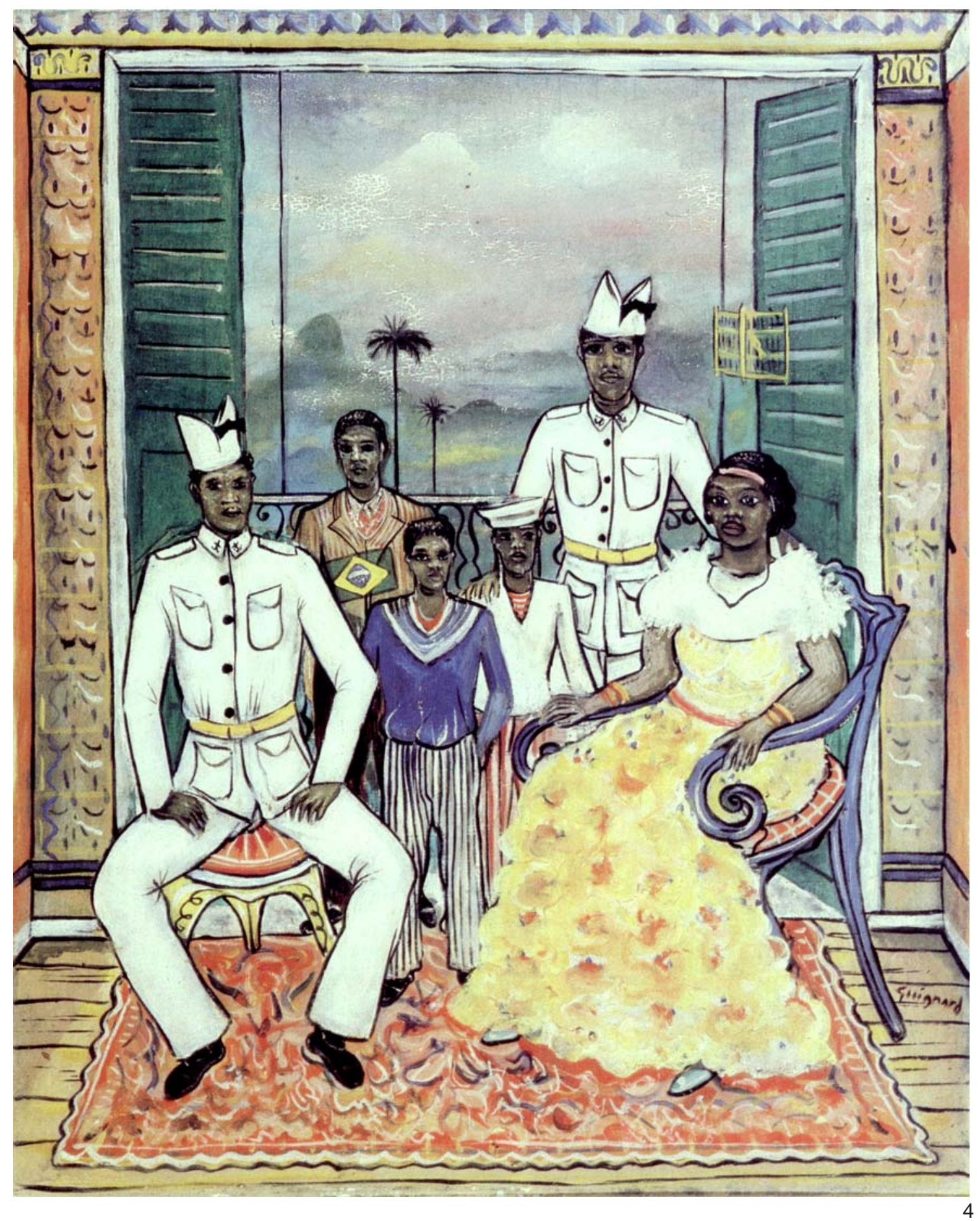




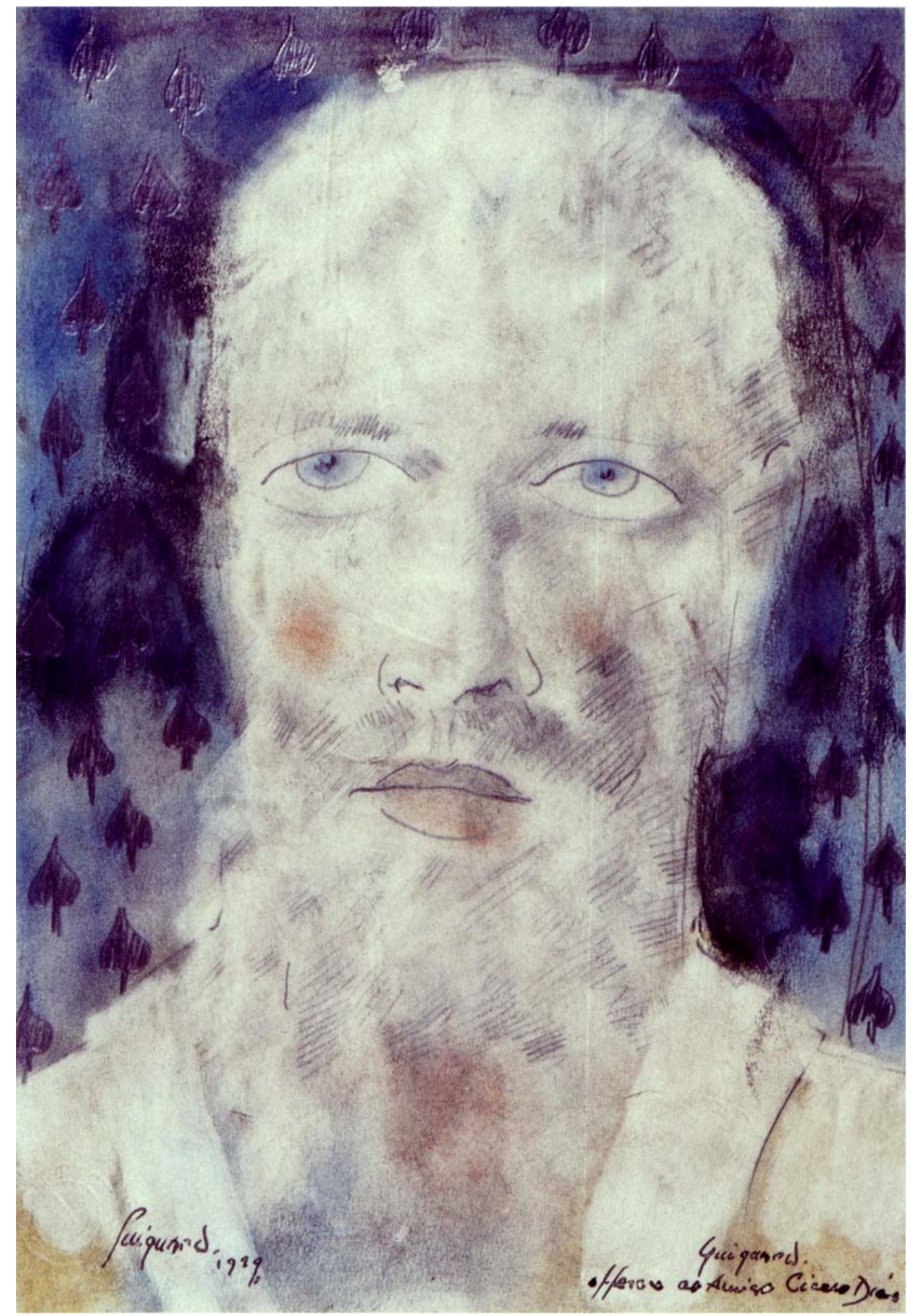

5 


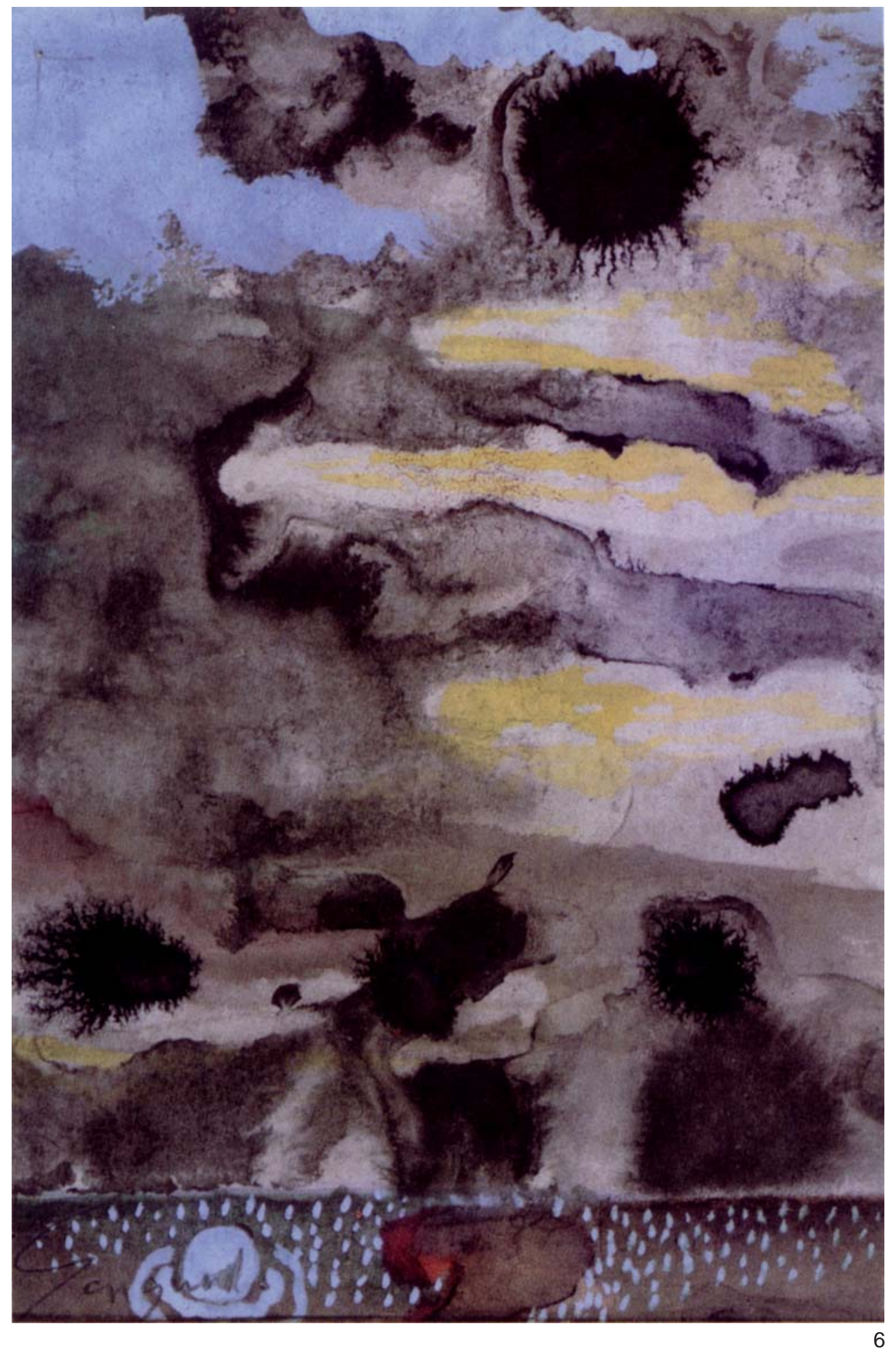




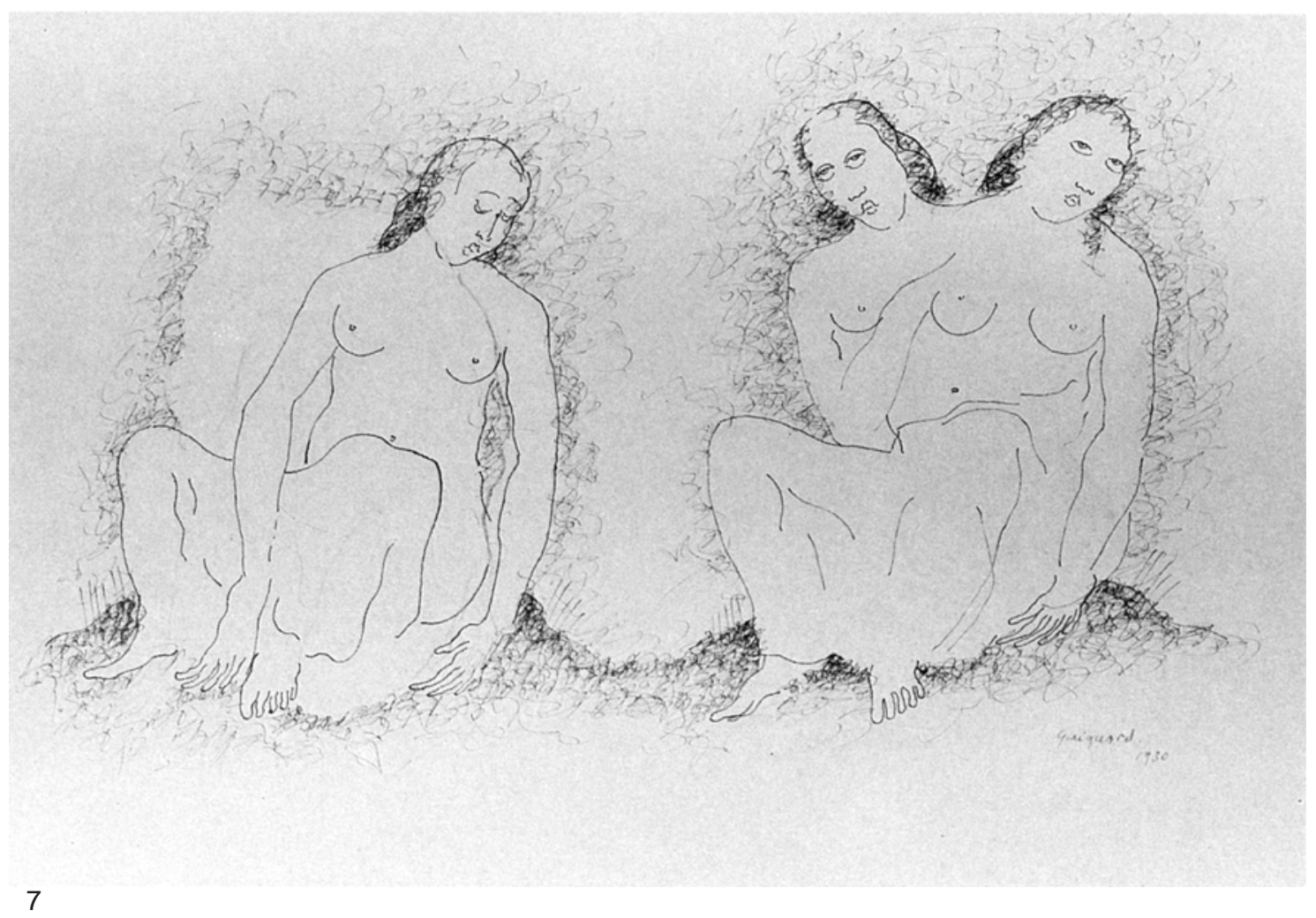




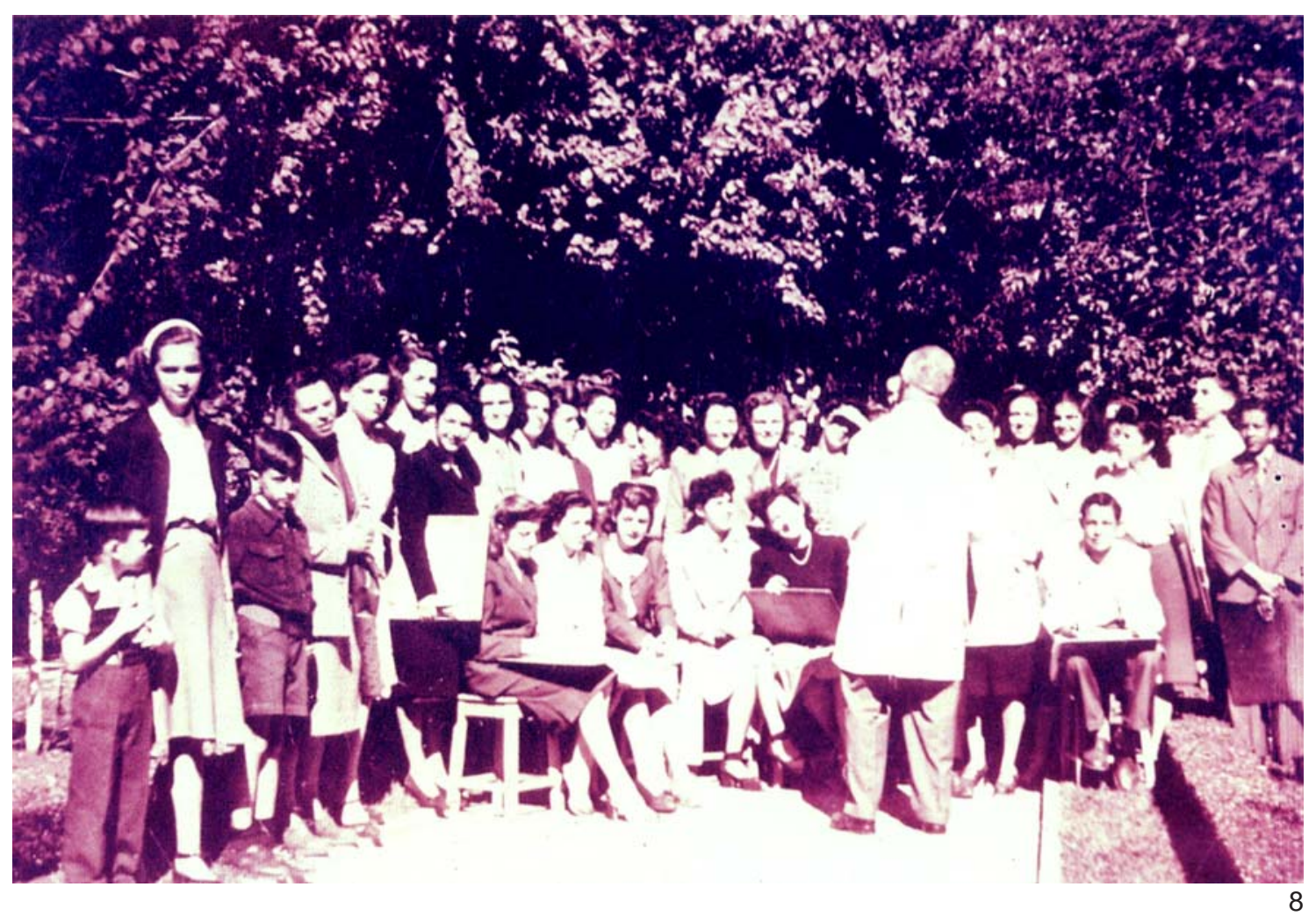


LEGENDAS:

1 Guignard em seu atelier - anos 50.

2 Auto-retrato, óleo s/tela, 1952. Acervo do Museu da Pampulha de Belo Horizonte.

3 Vaso com flores, óleo s/papelão, 1933. Coleção Mário de Andrade do Instituto de Estudos Brasileiros.

4 Familia do fuzleiro naval, óleo s/madeira. Coleção Mário de Andrade do Instituto de Estudos Brasileiros

5 Cabeça de velho, lápis e pastel s/papel, 1929. Coleção Mário de Andrade do Instituto de Estudos Brasileiros.

6 S/titulo, Aquarela s/papel, 1947. Coleção Maria Helena Andrés.

7 Três mulheres, nanquim preto e vermelho s/papel, 1930. Coleção Mário de Andrade do Instituto de Estudos Brasileiros.

8 Guignard e seus alunos no Parque Municipal de Belo Horizonte - anos 40. 